\title{
Antheraea pernyi Silk Fiber: A Potential Resource for Artificially Biospinning Spider Dragline Silk
}

\author{
Yaopeng Zhang, Hongxia Yang, Huili Shao, and Xuechao Hu \\ State Key Laboratory for Modification of Chemical Fibers and Polymer Materials, College of Material Science and Engineering, \\ Donghua University, Shanghai 201620, China \\ Correspondence should be addressed to Huili Shao, hlshao@dhu.edu.cn
}

Received 16 September 2009; Revised 8 January 2010; Accepted 1 March 2010

Academic Editor: Kenneth L. White

Copyright ( $) 2010$ Yaopeng Zhang et al. This is an open access article distributed under the Creative Commons Attribution License, which permits unrestricted use, distribution, and reproduction in any medium, provided the original work is properly cited.

\begin{abstract}
The outstanding properties of spider dragline silk are likely to be determined by a combination of the primary sequences and the secondary structure of the silk proteins. Antheraea pernyi silk has more similar sequences to spider dragline silk than the silk from its domestic counterpart, Bombyx mori. This makes it much potential as a resource for biospinning spider dragline silk. This paper further verified its possibility as the resource from the mechanical properties and the structures of the A. pernyi silks prepared by forcible reeling. It is surprising that the stress-strain curves of the $A$. pernyi fibers show similar sigmoidal shape to those of spider dragline silk. Under a controlled reeling speed of $95 \mathrm{~mm} / \mathrm{s}$, the breaking energy was $1.04 \times 10^{5} \mathrm{~J} / \mathrm{kg}$, the tensile strength was $639 \mathrm{MPa}$ and the initial modulus was $9.9 \mathrm{GPa}$. It should be noted that this breaking energy of the A. pernyi silk approaches that of spider dragline silk. The tensile properties, the optical orientation and the $\beta$-sheet structure contents of the silk fibers are remarkably increased by raising the spinning speeds up to $95 \mathrm{~mm} / \mathrm{s}$.
\end{abstract}

\section{Introduction}

Spider dragline silk exhibits exceptional strength, toughness, and resistance to mechanical compression, properties that rival those of synthetic high-performance fibers such as Kevlar [1-6]. Consequently, there is a wide spread interest in mimicking natural silks in order to produce new classes of high-performance materials [7-11]. The outstanding properties of spider dragline silk are likely to be determined by a combination of the primary sequences of the structural proteins of each silk $[12,13]$ and secondary structure of the silk which is affected by varying the processing conditions $[2,14,15]$. These features have led to a decade of effort to clone and express protein sequences of silks, with the aim of providing protein feedstocks from which to extrude filaments that reproduce the remarkable properties of silks in a more consistent and controlled fashion. Unfortunately the level of silk protein expression in heterologous systems to date, both in prokaryotes and eukaryotes, has been universally low $[3,16-20]$. Since no enough regenerated or recombinant spider dragline silk protein can be supplied for biospinning, it is necessary to find an appropriate resource to investigate the biospinning conditions. Bombyx mori silk fibroin was selected as a model system to artificially spin silk fiber by many researchers [21-23]. This is attributed to the similar spinning mechanism between silkworm and spider, and the similar amino acid composition between B. mori silk fibroin and spider dragline silk protein.

Comparing to the silk fibroin from domestic silkworm, B. mori, the silk fibroin from its wild counterpart, Antheraea pernyi (Chinese tussah), has more similar sequences to spider (major ampullate) silk, since it mainly consists of the repeated similar sequences by about 80 times where there are alternative appearances of the poly(L-alanine) region and the Gly-rich region [24-26]. In terms of the primary sequences of the structural proteins of each silk, A. pernyi silk fiber has much more potential as a resource for biospinning spider dragline silk than B. mori silk fiber. However, detailed comparison of the mechanical properties of $A$. pernyi silk fiber and spider dragline silk was not found. In addition, it has not been known how the processing conditions affect 
the performance and the structures of $A$. pernyi silk fiber, especially its secondary structure.

Many efforts have been made over the past decades on the artificial forcibly spinning of $B$. mori silk and spider dragline silk [2, 14, 27-30]. Like spider, immobilized silkworm under steady and controlled conditions produces stronger fibers than naturally spun ones at higher spinning speeds. So the production of silk fibers directly from silkworm before developing a cocoon is an extremely attractive and highly challenging objective in the emerging field of biomimetics. However, few studies on artificial reeling silk from $A$. perny $i$ were reported to date. The recent researches about A. pernyi silk were mainly focused on A. pernyi silk fiber modification [31, 32], A. pernyi silk fibroin dissolution [33, 34], regenerated A. pernyi silk fibroin film [35-38], and scaffolds from regenerated $A$. pernyi silk fibroin [39]. Moreover, report about regenerated A. pernyi silk fiber prepared by biomimetic spinning was also not found.

In this paper, the mechanical properties and structures of the silks rolled from an A. pernyi silkworm at controlled spinning speeds were investigated by using Instron material testing system, infrared spectroscope, optical polarizing microscope, and scanning electron microscope (SEM). Silks were also forcibly reeled from a $B$. mori silkworm and an Araneus ventricosus spider at the same conditions for comparison of their mechanical properties. In this work, we try to verify that $A$. pernyi silk fiber is a potential resource for artificially biospinning spider dragline silk.

\section{Experimental Section}

2.1. Preparation of Silk Fibers. An A. pernyi silkworm was obtained from Dandong, Liaoning province, China. It was fixed with tape on a plate at the end of the fifth larval instar to prevent the muscular action of its head and body. A single monofilament was drawn from the spinneret at $22^{\circ} \mathrm{C}$ onto a take-up spool that was driven by a motor positioned $10 \mathrm{~cm}$ before the spinneret. The silk was reeled from the silkworm at speeds in the range of 10 to $100 \mathrm{~mm} / \mathrm{s}$. The cocoon silk of A. pernyi without degumming was obtained from a cocoon spun by the above silkworm naturally.

Spider dragline silks and $B$. mori silks were also reeled forcibly at a speed of $10 \mathrm{~mm} / \mathrm{s}$ from an A. ventricosus spider and a $B$. mori silkworm, respectively.

2.2. Cross-Sectional Analysis of Silk Fibers. Silk fibers were embedded in black wool and were then cut into thin cross section slices $(20 \mu \mathrm{m}$ thick) by using Y172 fiber slice cutter (Changzhou No.1 Textile Equipment Co. Ltd., China). A microscope (BX-51, Olympus, Tokyo, Japan) was used to observe the cross section of the slices. Initial sample crosssectional areas were calculated from these measurements using Image-Pro Express (v 5.1; Media Cybernetics, Inc., Bethesda, MD, USA), assuming that sample volume is conserved during the tensile tests [28, 40]. The crosssectional areas were needed to rescale force-displacement plots as engineering stress-strain curves. Ten measurements were performed in each case.
2.3. Tensile Tests of Silk Fibers. Silk samples were cut and mounted on cardboard frames for tensile testing as described previously [27-29, 40, 41]. All measurements were carried out on an Instron 5565 materials testing machine (Instron, Canton, MA, USA) at a crosshead speed of $1 \mathrm{~mm} / \mathrm{min}$. The gauge length for the testes was $10 \mathrm{~mm}$. Twenty measurements were performed in each case at $22^{\circ} \mathrm{C}$ and $51 \%$ relative humidity.

2.4. Orientation of A. pernyi Silk Fibers. The birefringence index of $A$. pernyi silk fiber was measured using a polarized microscope (BX-51, Olympus, Tokyo, Japan) equipped with a thick Berek compensator. Twenty specimens were measured in each case. Optical orientation $f$ was evaluated according to the equation

$$
f=\frac{\Delta n}{I_{u}} \times 100(\%)
$$

in which $\Delta n$ and $I_{u}$ represent the birefringence of $A$. pernyi silk fiber and the ideal birefringence value (0.068) corresponding to the perfectly oriented fibroin molecules [42], respectively.

2.5. Conformation of A. pernyi Silk Fibers. Conformational characterization of $A$. pernyi silk fiber was performed by Fourier transform infrared spectroscopy (FT-IR) with a Nicolet Nexus-670 FT-IR spectrometer. Spectra were recorded with the $\mathrm{KBr}$ pellet technique. The crystallinity index was calculated according to the equation [36]

$$
\text { Crystallinity index }=\frac{I_{996}}{I_{660}}
$$

where $I_{996}$ is the intensity of amide IV component at $966 \mathrm{~cm}^{-1}$ (attributed to $\beta$-sheet structure) and $I_{660}$ is the intensity of amide $\mathrm{V}$ component at $660 \mathrm{~cm}^{-1}$ (attributed to random coil).

2.6. Surface Morphology of A. pernyi Silk Fibers. Surface morphology was observed through a SEM (JSM-5600LV, JEOL, Japan) at $10 \mathrm{kV}$ after gold coating.

\section{Results and Discussion}

3.1. Mechanical Characteristics of A. pernyi Silk Fibers and the Effects of Spinning Speed on Their Mechanical Properties. Figure 1(a) shows the stress-strain curves of the $A$. pernyi fibers obtained at different spinning speeds and the $A$. pernyi cocoon silk without degumming. To compare the mechanical characteristics of $A$. pernyi silk, $A$. ventricosus spider dragline silk, and $B$. mori silk, the stress-strain curves of these silks reeled at $10 \mathrm{~mm} / \mathrm{s}$ are shown in Figures 1(b), 1(c), and 1(d), respectively. It can be noticed that the stressstrain curves of the $A$. pernyi fibers show similar sigmoidal shape to that of the A. ventricosus spider. Three regions can be distinguished in the curves of Figures 1(a), 1(b), and 1(c): an initial linear elastic region (A), a yield region (B), and a hardening region $(\mathrm{C})$. The dragline silks of Argiope 


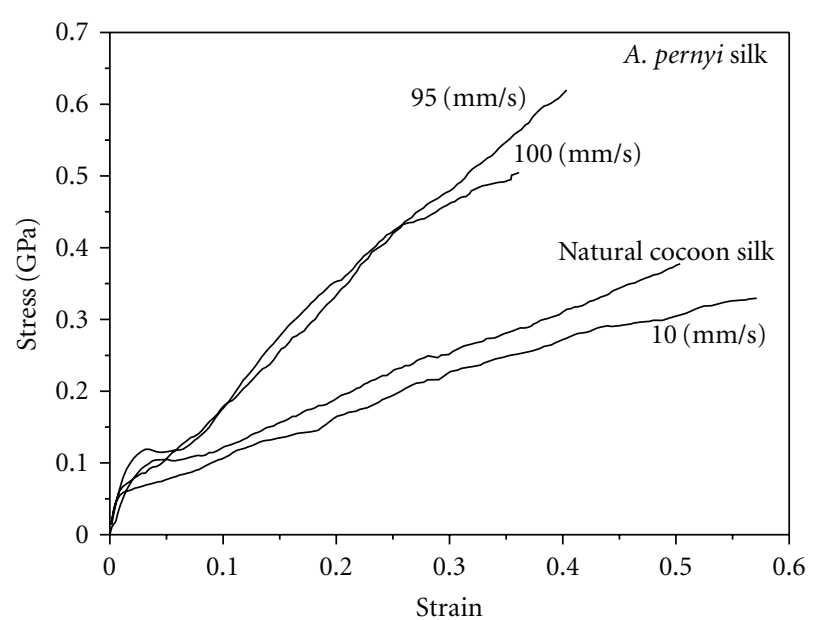

(a)

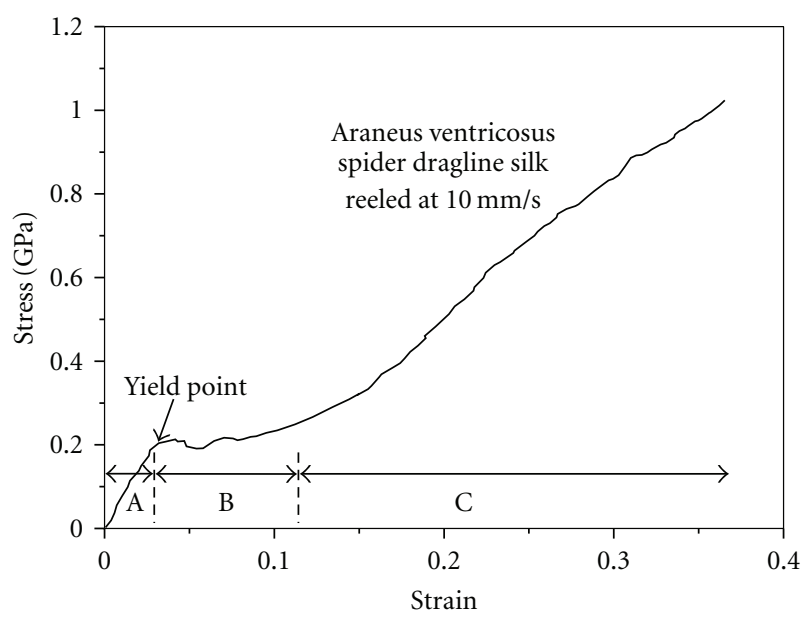

(c)

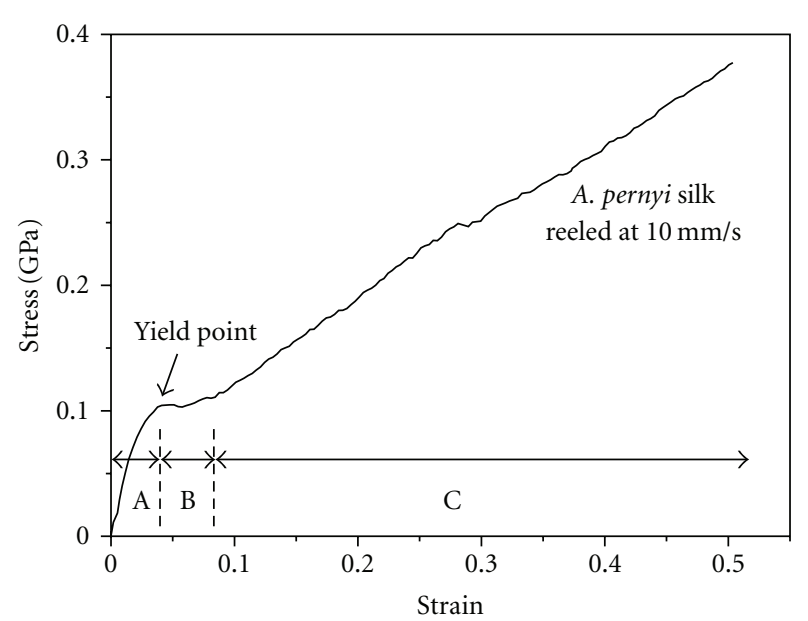

(b)

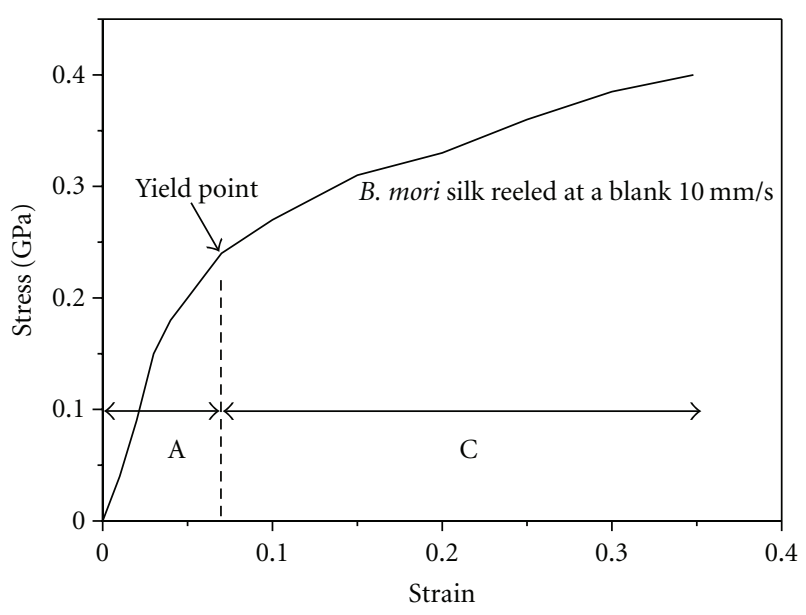

(d)

FIGURE 1: Stress-strain curves of (a) A. pernyi silks obtained at different spinning speeds, natural cocoon silk of A. pernyi, (b) A. pernyi silk, (c) A. ventricosus spider dragline silk and (d) B. mori silk forcibly reeled at $10 \mathrm{~mm} / \mathrm{s}$.

trifasciata [40], Nephila pilipes [43], and Nephila edulis $[2,44]$ also exhibited consistent stress-strain curves with Figure 1(c). The sigmoidal "rubber-like" shape of the stressstrain curves appears to be a common feature characterizing spider dragline silk and A. pernyi silk.

In Figure 1(d), the stress-strain curve of the B. mori fiber also starts with an elastic region (A). However, this region is followed directly by strain hardening where the stress increases nonlinearly with strain (C). For the B. mori silks forcibly reeled at other speeds and the naturally spun B. mori silks $[14,30,45]$, similar stress-strain curve shapes to Figure 1(d) were also reported. These curves are much different from those of spider dragline silk and A. pernyi silk. Hence, in terms of the stress-strain curves, the A. pernyi silks are more similar to the spider dragline silks than to the $B$. mori silks.

Since the average spinning speed of silkworm for cocoon spinning is $9.4-9.6 \mathrm{~mm} / \mathrm{s}$ [46], the initial reeling speed for A. pernyi was set as $10 \mathrm{~mm} / \mathrm{s}$. As shown in Figure 1(a), the stress-strain curve of the forcibly reeled A. pernyi silk fiber at $10 \mathrm{~mm} / \mathrm{s}$ is close to the curve of the natural cocoon silk of A. pernyi, when the latter is compared to the other two curves of the A. pernyi silk fibers reeled at 95 and $100 \mathrm{~mm} / \mathrm{s}$.

When the reeling speed increases from 10 to $100 \mathrm{~mm} / \mathrm{s}$, no obvious change is observed for the shapes of the stressstrain curves. However, there are a noticeably increasing tendency of tensile strength and a decreasing tendency of strain at breaking with increasing speed. From the above stressstrain curves, tensile strength, elastic modulus, breaking energy, and strain at breaking of the A. pernyi silk fibers are obtained and shown in Table 1. The effects of spinning speed on the tensile strength and elastic modulus of $A$. pernyi silk fibers are shown in Figure 2. Our data indicate that the tensile strength and initial modulus increase with reeling speed up to $95 \mathrm{~mm} / \mathrm{s}$. However, both the tensile strength and initial modulus decrease, when the reeling speed increases from 95 to $100 \mathrm{~mm} / \mathrm{s}$. On one occasion, we attempted to draw silk at very high speeds above $100 \mathrm{~mm} / \mathrm{s}$, but this resulted in thread breaking within a few seconds from the onset of reeling. Table 1 shows the detailed mechanical parameters 


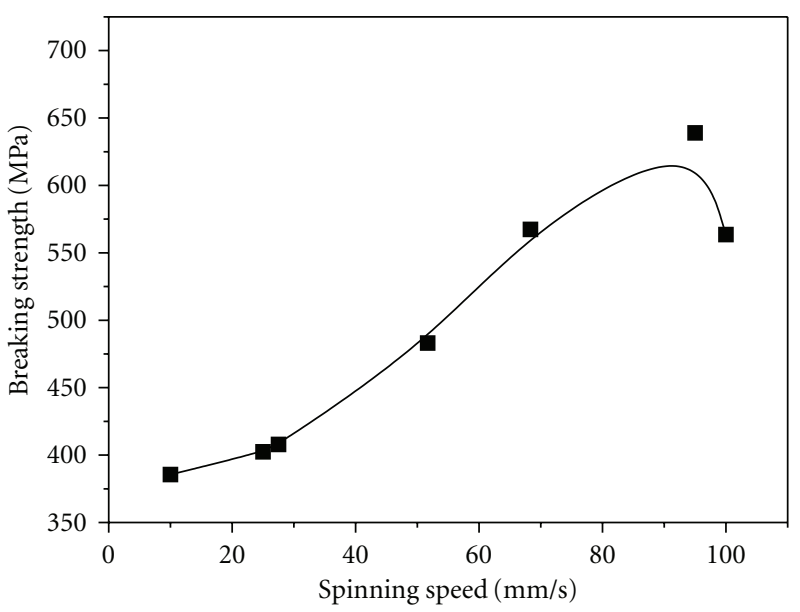

(a)

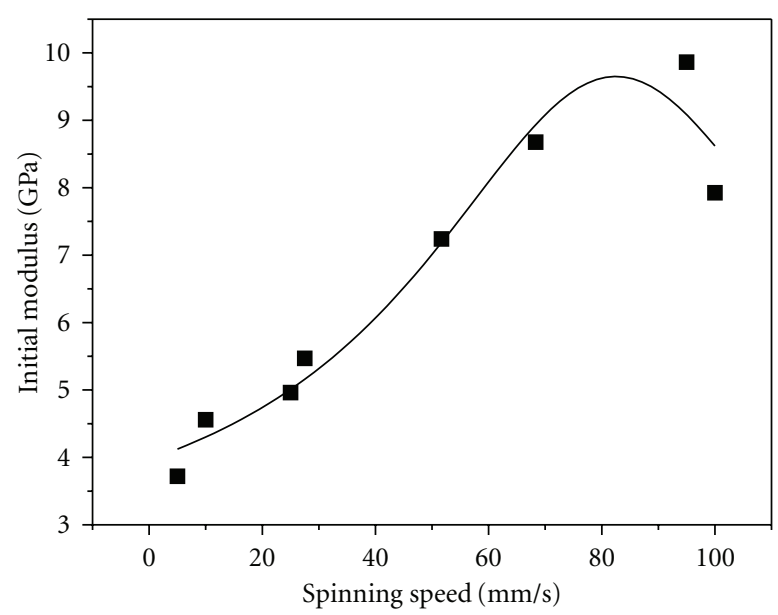

(b)

FIGURE 2: Effects of the spinning speed on (a) the tensile strength, and (b) the initial modulus of A. pernyi silk fibers.

TABle 1: Comparison of mechanical properties, optical orientation and crystallinity index of $A$. pernyi silks, A. ventricosus spider dragline silk, and B. mori silk.

\begin{tabular}{|c|c|c|c|c|c|c|c|}
\hline Silk & $\begin{array}{l}\text { Spinning speed } \\
(\mathrm{mm} / \mathrm{s})\end{array}$ & $\begin{array}{c}\text { Tensile } \\
\text { strength }(\mathrm{MPa})\end{array}$ & $\begin{array}{c}\text { Initial } \\
\text { modulus } \\
(\mathrm{GPa})\end{array}$ & $\begin{array}{c}\text { Breaking } \\
\text { energy } \\
\left(\times 10^{5} \mathrm{~J} / \mathrm{kg}\right) \\
\end{array}$ & $\begin{array}{l}\text { Strain at } \\
\text { breaking }\end{array}$ & $\begin{array}{c}\text { Optical } \\
\text { orientation } \\
(\%) \\
\end{array}$ & $\begin{array}{c}\text { Crystallinity } \\
\text { index }\end{array}$ \\
\hline \multirow{8}{*}{ A. pernyi silk } & 10 & 386 & 4.6 & 0.75 & 0.56 & 27.2 & 0.69 \\
\hline & 25 & 403 & 5.0 & 0.61 & 0.37 & 36.0 & 0.73 \\
\hline & 28 & 408 & 5.5 & 0.81 & 0.50 & 37.4 & 0.74 \\
\hline & 52 & 483 & 7.2 & 0.63 & 0.32 & 39.4 & 0.76 \\
\hline & 68 & 567 & 8.7 & 0.73 & 0.31 & 41.5 & 0.80 \\
\hline & 95 & 639 & 9.9 & 1.04 & 0.40 & 46.4 & 0.84 \\
\hline & 100 & 564 & 7.9 & 0.84 & 0.37 & 54.0 & 0.77 \\
\hline & $\begin{array}{c}\text { Natural } \\
\text { spinning }\end{array}$ & 362 & 4.8 & 0.64 & 0.50 & 20.4 & 0.71 \\
\hline $\begin{array}{l}\text { A. ventricosus } \\
\text { spider dragline } \\
\text { silk }\end{array}$ & 10 & 1020 & 7.6 & 1.34 & 0.37 & - & - \\
\hline B. mori silk & 10 & 400 & 4.0 & 0.76 & 0.35 & - & - \\
\hline
\end{tabular}

of the $A$. pernyi silks, $A$. ventricosus dragline silk, and $B$. mori silk. At $95 \mathrm{~mm} / \mathrm{s}$, the average tensile strength of $A$. pernyi silk was $639 \mathrm{MPa}$, the initial modulus was $9.9 \mathrm{GPa}$ and the breaking energy was $1.04 \times 10^{5} \mathrm{~J} / \mathrm{kg}$. Compared to the breaking energy of the $B$. mori silk reeled forcibly at $10 \mathrm{~mm} / \mathrm{s}\left(0.76 \times 10^{5} \mathrm{~J} / \mathrm{kg}\right)$, the breaking energy of the $A$. pernyi silk reeled at $95 \mathrm{~mm} / \mathrm{s}$ approaches that of the spider dragline silk reeled at $10 \mathrm{~mm} / \mathrm{s}\left(1.34 \times 10^{5} \mathrm{~J} / \mathrm{kg}\right)$. Shao and Vollrath reported the breaking energy of the naturally spun B. mori silk is $0.60 \times 10^{5} \mathrm{~J} / \mathrm{kg}$ [14], while Vollrath reported that of the $N$. edulis spider dragline silk reeled at $20 \mathrm{~mm} / \mathrm{s}$ is $1.65 \pm 0.3 \times 10^{5} \mathrm{~J} / \mathrm{kg}$ [2]. In comparison with these data, the $A$. pernyi silk reeled at $95 \mathrm{~mm} / \mathrm{s}$ also exhibits impressive toughness which is an unsurpassed property of spider dragline silk.

Moreover, the tensile strengths of the $A$. pernyi silk fibers obtained by forcibly silking at faster speeds are remarkably higher than those of naturally spun silk fibers of $A$. perny $i$ and B. mori $(500 \mathrm{MPa})[14]$. This is consistent with the results of $B$. mori silks which were obtained by forced silking $[27,30]$. From the above results, it is revealed that like the spider dragline silk and $B$. mori silk, silk fiber with considerably higher strength can be able to be produced from $A$. pernyi silkworm by forcibly silking at faster spinning speed. It may be possible to produce high performance fiber by using $A$. pernyi silk fibroin as a resource for dissolution, regeneration, and artificially spinning.

3.2. The Effects of Spinning Speed on the Crystalline Structure and Molecular Orientation of A. pernyi Silk Fibers. FTIR spectroscopy is useful in structural analysis of silk fibroin, because the position and intensity of the amide bands are sensitive to the molecular conformation. The native and regenerated $A$. pernyi silk fibroin usually shows the 


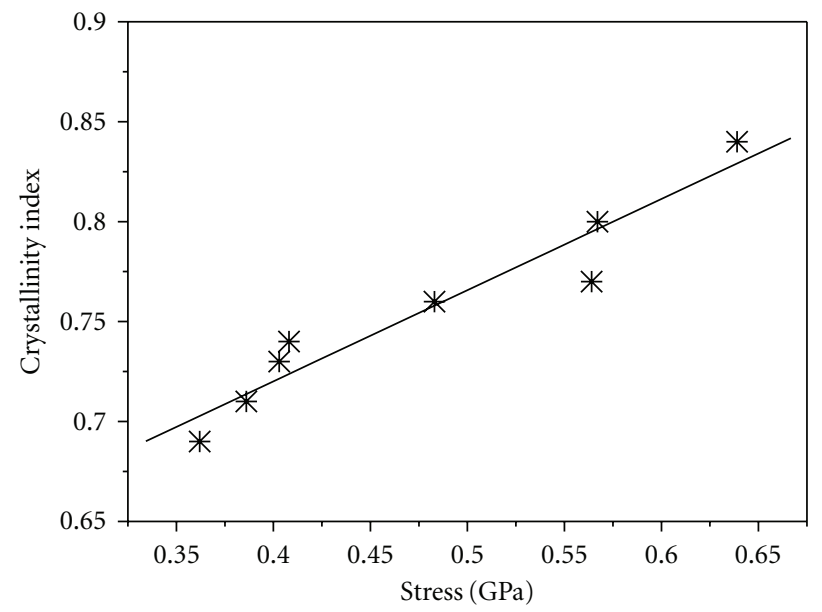

(a)

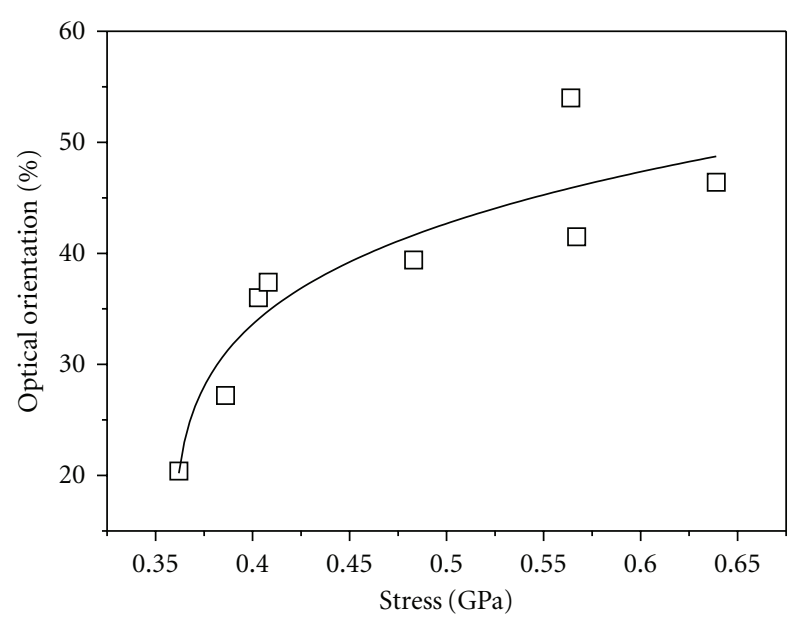

(b)

FIgURE 3: (a) Relation between crystallinity index and breaking stress of A. pernyi silks and (b) relation between optical orientation and breaking stress of $A$. pernyi silks.

characteristic absorption bands at 1660 (amide I), 1550 (amide II), 1270 (amide III), 896 (amide IV), and $620 \mathrm{~cm}^{-1}$ (amide V), representing $\alpha$-helix conformation, and $660 \mathrm{~cm}^{-1}$ (amide V), attributed to random coil conformation [37]. Moreover, A. pernyi silk fibroin shows strong absorption bands at 1630 (amide I), 1520 (amide II), 1220 (amide III), 966 (amide IV), and $700 \mathrm{~cm}^{-1}$ (amide V), attributed to $\beta$-sheet conformation [36]. Therefore, the conformational changes of $A$. pernyi silk fibers can be examined for the effect of spinning speed on silk structure. As crystallinity index is calculated as the intensity ratio of the amide IV component at $966 \mathrm{~cm}^{-1}$ to the amide $\mathrm{V}$ component at $660 \mathrm{~cm}^{-1}$ from FTIR spectra, high value of the crystallinity index suggests high content of the $\beta$-sheet conformation and perfect crystalline region of the fiber.

Table 1 shows the optical orientation and crystallinity index of the A. pernyi silk fibers. With increasing the spinning speed below $100 \mathrm{~mm} / \mathrm{s}$, both the optical orientation and crystallinity index increase accordingly. This result implies that the molecular chain orientation of silk fibroin and the $\beta$-sheet crystallization can be promoted by enhancing the artificial spinning speed. We think the fine structural changes of the A. pernyi silk fibers were induced by stress, since the silk fibroin chains were stretched more in the spinning direction during forcible silking. As a result, more silk fibroin molecules were transferred from the $\alpha$-helix/random coil to the $\beta$-sheet conformation in the case of higher spinning speed. From the relations of crystallinity-stress and orientation-stress presented in Figure 3, it can be known that the breaking stress of $A$. perny $i$ silk increases linearly with the crystallinity index. The breaking stress also increases with the degree of orientation, although the increase is nonlinear. Du et al. found the similar relation between orientation function and stress of spider dragline silk [43]. Because silk strength is widely attributed to crystalline $\beta$-sheet structures, while elasticity is generally thought to involve amorphous regions [47], the above relations imply that more crystallites become aligned and nearly parallel to the fiber axis. Hence, the highly oriented crystallites are in good position to support the load.

However, it can be known from Figure 2 that the tensile strength and initial modulus of the $A$. pernyi silk fibers drops from 639 to $564 \mathrm{MPa}$, when the reeling speed rises from 95 to $100 \mathrm{~mm} / \mathrm{s}$. We found that thread is difficult to be reeled continuously at $100 \mathrm{~mm} / \mathrm{s}$ or higher speed, because insufficient spinning dope could be supplied by the A. pernyi silkworm. When the spinning dope flows from the posterior division to the anterior division and spinning duct, silkworm dynamically adjusts the contents and conditions of the spinning dope, such as $\mathrm{pH}$, metal ions, fibroin concentration, elongation and shearing conditions [48]. The spinning dope with appropriate compositions is then transformed to liquid crystalline and spun out from the orifice of the duct. This indicates that silkworm needs time to adjust the compositions during spinning. In the case of $100 \mathrm{~mm} / \mathrm{s}$, which is ten fold of the natural spinning speed, the adjusting time is too short for the silkworm to supply enough dope with appropriate compositions. Therefore, some defects of molecular aggregation are formed during the liquid crystalline spinning process. This results in the decrease of the crystallinity index from 0.84 to 0.77 as shown in Table 1. From this Table, it is also known that the optical orientation increases from $46.4 \%$ to $54.0 \%$. This is because the fibroin chains are extended greatly in the direction of fiber axis under high shearing and elongation force, when the silk is stretched at high speed. Even though the optical orientation represents total molecular orientation, the decrease of the crystallinity index predominantly causes less oriented $\beta$-sheet crystallites, which contribute to the drop of the tensile strength at the reeling speed of $100 \mathrm{~mm} / \mathrm{s}$.

3.3. The Effects of Spinning Speed on the Surface Morphology of A. pernyi Silk Fibers. Three SEM images of the surfaces of $A$. pernyi silk fibers obtained at different spinning speeds are given in Figure 4. It can be seen that the surface 


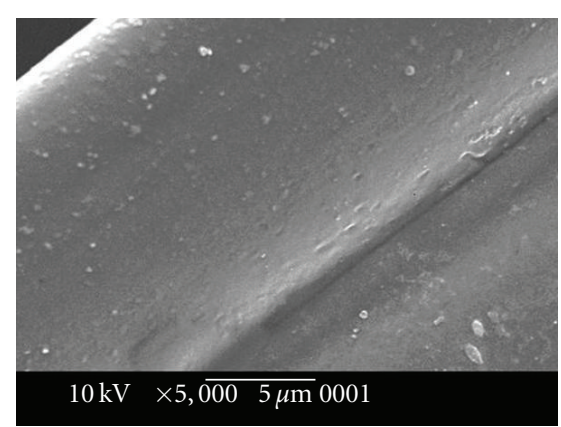

(a)

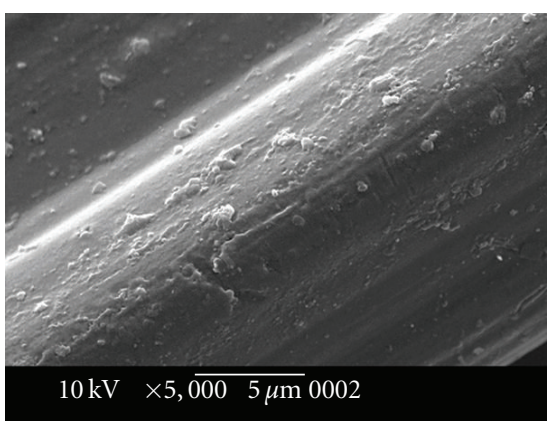

(b)

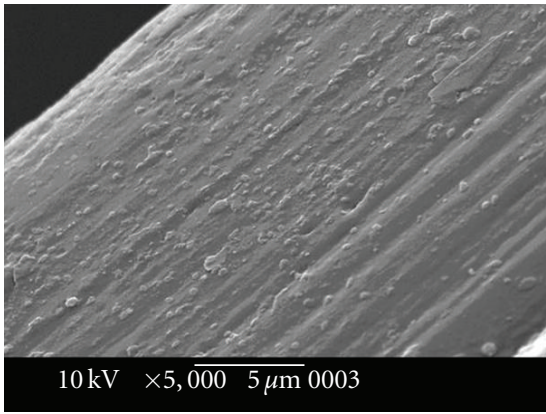

(c)

FIGURE 4: SEM images of the surfaces of the A. pernyi silks obtained at different spinning speeds: (a) $25 \mathrm{~mm} / \mathrm{s}$, (b) $68 \mathrm{~mm} / \mathrm{s}$, and (c) $100 \mathrm{~mm} / \mathrm{s}$.

morphology is obviously affected by the spinning speed. Some longitudinal cracking lines appear and the fiber surface becomes rough when the spinning speed increases. This is probably because the sericin shell or silk fibroin core of the fiber partially ruptures during forcibly silking at higher reeling speeds. Thus the morphological defects also possibly cause the drop of the tensile strength when the reeling speed rises from 95 to $100 \mathrm{~mm} / \mathrm{s}$. The rough surface may be further related to sericin coating. As we mentioned previously, insufficient spinning dope could be supplied by the A. pernyi silkworm at $100 \mathrm{~mm} / \mathrm{s}$ or higher speed. Therefore, the silk fibroin core of the fiber cannot be fully coated with sericin at the spinneret orifice of the silkworm. Comparing to silk fibroin, sericin makes minor contribution to the mechanics of silk fiber. However, it was reported that sericin could induce the transition of silk fibroin from the random coil or $\alpha$-helix to the $\beta$-sheet structure, and further improve the mechanical properties of silk fibroin fibers [49]. The incomplete or ruptured sericin coating is one of the possible reasons for the decrease of the crystallinity index when the reeling speed rises from 95 to $100 \mathrm{~mm} / \mathrm{s}$.

\section{Conclusions}

Silk fibers are obtained from an A. pernyi silkworm by forcibly silking at the speed from 10 to $100 \mathrm{~mm} / \mathrm{s}$ and their structural characteristics are evaluated. Like the spider dragline silk, the A. pernyi silk fiber exhibits three regions in its stress-strain curve, including an initial linear elastic region, a yield region, and a hardening region. Our findings indicate that the mechanical properties of the A. pernyi silk fiber depend crucially on spinning conditions. The A. pernyi silks can be made stronger, stiffer simply by adjusting the reeling speed. The tensile strength and initial modulus of the $A$. pernyi silk fiber increase with the reeling speed in the range of 10 to $95 \mathrm{~mm} / \mathrm{s}$. The A. pernyi silk reeled at $95 \mathrm{~mm} / \mathrm{s}$ presents a breaking energy of $1.04 \times 10^{5} \mathrm{~J} / \mathrm{kg}$, which approaches that of the spider dragline silk. The crystallinity and orientation are important structural factors to decide the strength of A. pernyi silk. Enhancement of the silk strength can be achieved by increasing the degrees of orientation and crystallinity.
There are many similarities between the spider dragline silk and the $A$. pernyi silk, such as protein sequence, tensile properties, relation between structure and mechanical properties. This makes the A. pernyi silk fibroin more attractive to be a model system for biospinning silk fiber than $B$. mori silk fibroin. It might be even possible to artificially prepare stronger fibers than spider dragline silk from regenerated $A$. pernyi silk fibroin at appropriate spinning conditions.

\section{Acknowledgments}

This work is supported by the National Nature Science Foundation of China (50803011), Specialized Research Fund for the Doctoral Program of Higher Education (200802550001), the Scientific Research Foundation for the Returned Overseas Chinese Scholars, State Education Ministry, Shanghai Educational Development Foundation (2007CG44), Shanghai Pujiang Program (09PJ1400700), the Fundamental Research Funds for the Central Universities, and the Programme of Introducing Talents of Discipline to Universities (111-2-04).

\section{References}

[1] F. Vollrath and D. P. Knight, "Liquid crystalline spinning of spider silk," Nature, vol. 410, no. 6828, pp. 541-548, 2001.

[2] F. Vollrath, B. Madsen, and Z. Shao, "The effect of spinning conditions on the mechanics of a spider's dragline silk," Proceedings of the Royal Society B, vol. 268, no. 1483, pp. 23392346, 2001.

[3] A. Lazaris, S. Arcidiacono, Y. Huang, et al., "Spider silk fibers spun from soluble recombinant silk produced in mammalian cells," Science, vol. 295, no. 5554, pp. 472-476, 2002.

[4] D. A. Tirrell, "Putting a new spin on spider silk," Science, vol. 271, no. 5245, pp. 39-40, 1996.

[5] M. B. Hinman, J. A. Jones, and R. V. Lewis, "Synthetic spider silk: a modular fiber," Trends in Biotechnology, vol. 18, no. 9, pp. 374-379, 2000.

[6] A. Glisovic, T. Vehoff, R. J. Davies, and T. Salditt, "Strain dependent structural changes of spider dragline silk," Macromolecules, vol. 41, no. 2, pp. 390-398, 2008.

[7] J. P. O’Brien, S. R. Fahnestock, Y. Termonia, and K. H. Gardner, "Nylons from nature: synthetic analogs to spider silk," Advanced Materials, vol. 10, no. 15, pp. 1185-1195, 1998. 
[8] F. Teule, W. A. Furin, A. R. Cooper, J. R. Duncan, and R. V. Lewis, "Modifications of spider silk sequences in an attempt to control the mechanical properties of the synthetic fibers," Journal of Materials Science, vol. 42, no. 21, pp. 8974-8985, 2007.

[9] L. Romer and T. Scheibel, "Basis for new materials—spider silk proteins," Chemie in Unserer Zeit, vol. 41, no. 4, pp. 306-314, 2007.

[10] H.-T. Xu, B.-L. Fan, S.-Y. Yu, et al., "Construct synthetic gene encoding artificial spider dragline silk protein and its expression in milk of transgenic mice," Animal Biotechnology, vol. 18, no. 1, pp. 1-12, 2007.

[11] A. Seidel, O. Liivak, and L. W. Jelinski, "Artificial spinning of spider silk,” Macromolecules, vol. 31, no. 19, pp. 6733-6736, 1998.

[12] C. Vendrely and T. Scheibel, "Biotechnological production of spider-silk proteins enables new applications," Macromolecular Bioscience, vol. 7, no. 4, pp. 401-409, 2007.

[13] A. Rising, H. Nimmervoll, S. Grip, et al., "Spider silk proteins-mechanical property and gene sequence," Zoological Science, vol. 22, no. 3, pp. 273-281, 2005.

[14] Z. Shao and F. Vollrath, "Surprising strength of silkworm silk," Nature, vol. 418, no. 6899, p. 741, 2002.

[15] B. Madsen, Z. Z. Shao, and F. Vollrath, "Variability in the mechanical properties of spider silks on three levels: interspecific, intraspecific and intraindividual," International Journal of Biological Macromolecules, vol. 24, no. 2-3, pp. 301306, 1999.

[16] J. T. Prince, K. P. McGrath, C. M. DiGirolamo, and D. L. Kaplan, "Construction, cloning, and expression of synthetic genes encoding spider dragline silk," Biochemistry, vol. 34, no. 34, pp. 10879-10885, 1995.

[17] S. R. Fahnestock and S. L. Irwin, "Synthetic spider dragline silk proteins and their production in Escherichia coli," Applied Microbiology and Biotechnology, vol. 47, no. 1, pp. 23-32, 1997.

[18] S. Arcidiacono, C. Mello, D. Kaplan, S. Cheley, and H. Bayley, "Purification and characterization of recombinant spider silk expressed in Escherichia coli," Applied Microbiology and Biotechnology, vol. 49, no. 1, pp. 31-38, 1998.

[19] J. Scheller, K.-H. Guhrs, F. Grosse, and U. Conrad, "Production of spider silk proteins in tobacco and potato," Nature Biotechnology, vol. 19, no. 6, pp. 573-577, 2001.

[20] C. W. P. Foo and D. L. Kaplan, "Genetic engineering of fibrous proteins: spider dragline silk and collagen," Advanced Drug Delivery Reviews, vol. 54, no. 8, pp. 1131-1143, 2002.

[21] K. Matsumoto, H. Uejima, T. Iwasaki, Y. Sano, and H. Sumino, "Studies on regenerated protein fibers. III. Production of regenerated silk fibroin fiber by the self-dialyzing wet spinning method," Journal of Applied Polymer Science, vol. 60, no. 4, pp. 503-511, 1996.

[22] M. Wang, J. H. Yu, D. L. Kaplan, and G. C. Rutledge, "Production of submicron diameter silk fibers under benign processing conditions by two-fluid electrospinning," Macromolecules, vol. 39, no. 3, pp. 1102-1107, 2006.

[23] S.-W. Ha, A. E. Tonelli, and S. M. Hudson, "Structural studies of bombyx mori silk fibroin during regeneration from solutions and wet fiber spinning," Biomacromolecules, vol. 6, no. 3, pp. 1722-1731, 2005.

[24] Y. Nakazawa and T. Asakura, "High-resolution c- $13 \mathrm{cp} / \mathrm{mas}$ NMR study on structure and structural transition of Antheraea pernyi silk fibroin containing poly(L-alanine) and Gly-rich regions," Macromolecules, vol. 35, no. 6, pp. 2393-2400, 2002.
[25] Y. Nakazawa, T. Nakai, T. Kameda, and T. Asakura, "A 13C NMR study on the structural change of silk fibroin from Samia cynthia ricini," Chemical Physics Letters, vol. 311, no. 5, pp. 362-366, 1999.

[26] H. Sezutsu and K. Yukuhiro, "Dynamic rearrangement within the Antheraea pernyi silk fibroin gene is associated with four types of repetitive units," Journal of Molecular Evolution, vol. 51, no. 4, pp. 329-338, 2000.

[27] J. Perez-Rigueiro, M. Elices, J. Llorca, and C. Viney, "Tensile properties of silkworm silk obtained by forced silking," Journal of Applied Polymer Science, vol. 82, no. 8, pp. 1928-1935, 2001.

[28] J. Perez-Rigueiro, C. Viney, J. Llorca, and M. Elices, "Silkworm silk as an engineering material," Journal of Applied Polymer Science, vol. 70, no. 12, pp. 2439-2447, 1998.

[29] J. Perez-Rigueiro, C. Viney, J. Llorca, and M. Elices, "Mechanical properties of single-brin silkworm silk," Journal of Applied Polymer Science, vol. 75, no. 10, pp. 1270-1277, 2000.

[30] M. M. R. Khan, H. Morikawa, Y. Gotoh, et al., "Structural characteristics and properties of Bombyx mori silk fiber obtained by different artificial forcibly silking speeds," International Journal of Biological Macromolecules, vol. 42, no. 3, pp. 264-270, 2008.

[31] Y. Kawahara and M. Shioya, "Mechanical properties of tussah silk fibers treated with methacrylamide," Journal of Applied Polymer Science, vol. 65, no. 10, pp. 2051-2057, 1997.

[32] M. Tsukada, G. Freddi, M. R. Massafra, and S. Beretta, "Structure and properties of tussah silk fibers graft-copolymerized with methacrylamide and 2-hydroxyethyl methacrylate," Journal of Applied Polymer Science, vol. 67, no. 8, pp. 1393-1403, 1998.

[33] H. Kweon and Y. H. Park, "Dissolution and characterization of regenerated Antheraea pernyi silk fibroin," Journal of Applied Polymer Science, vol. 82, no. 3, pp. 750-758, 2001.

[34] W. Tao, M. Li, and C. Zhao, "Structure and properties of regenerated Antheraea pernyi silk fibroin in aqueous solution," International Journal of Biological Macromolecules, vol. 40, no. 5, pp. 472-478, 2007.

[35] H. Kweon, S. O. Woo, and Y. H. Park, "Effect of heat treatment on the structural and conformational changes of regenerated Antheraea pernyi silk fibroin films," Journal of Applied Polymer Science, vol. 81, no. 9, pp. 2271-2276, 2001.

[36] H. Y. Kweon and Y. H. Park, "Structural and conformational changes of regenerated Antheraea pernyi silk fibroin films treated with methanol solution," Journal of Applied Polymer Science, vol. 73, no. 14, pp. 2887-2894, 1999.

[37] H. Y. Kweon, I. C. Um, and Y. H. Park, "Thermal behavior of regenerated Antheraea pernyi silk fibroin film treated with aqueous methanol," Polymer, vol. 41, no. 20, pp. 7361-7367, 2000.

[38] M. Li, W. Tao, S. Lu, and S. Kuga, "Compliant film of regenerated Antheraea pernyi silk fibroin by chemical crosslinking," International Journal of Biological Macromolecules, vol. 32, no. 3-5, pp. 159-163, 2003.

[39] M. Li, W. Tao, S. Lu, and C. Zhao, "Porous 3-D scaffolds from regenerated Antheraea pernyi silk fibroin," Polymers for Advanced Technologies, vol. 19, no. 3, pp. 207-212, 2008.

[40] M. A. Garrido, M. Elices, C. Viney, and J. Perez-Rigueiro, "The variability and interdependence of spider drag line tensile properties," Polymer, vol. 43, no. 16, pp. 4495-4502, 2002.

[41] M. A. Garrido, M. Elices, C. Viney, and J. Perez-Rigueiro, "Active control of spider silk strength: comparison of drag line spun on vertical and horizontal surfaces," Polymer, vol. 43, no. 4, pp. 1537-1540, 2001. 
[42] M. Tsukada, H. Kato, G. Freddi, N. Kasai, and H. Ishikawa, "Structural changes and dyeability of silk fibroin fiber following shrinkage in neutral salt solution," Journal of Applied Polymer Science, vol. 51, no. 4, pp. 619-624, 1994.

[43] N. Du, X. Y. Liu, J. Narayanan, L. Li, M. L. M. Lim, and D. Li, "Design of superior spider silk: from nanostructure to mechanical properties," Biophysical Journal, vol. 91, no. 12, pp. 4528-4535, 2006.

[44] J. Sirichaisit, R. J. Young, and F. Vollrath, "Molecular deformation in spider dragline silk subjected to stress," Polymer, vol. 41, no. 3, pp. 1223-1227, 2000.

[45] J. Perez-Rigueiro, M. Elices, J. Llorca, and C. Viney, "Effect of degumming on the tensile properties of silkworm (Bombyx mori) silk fiber," Journal of Applied Polymer Science, vol. 84, no. 7, pp. 1431-1437, 2002.

[46] M. Kiyosawa, E. Ito, K. Shirai, R. Kanekatsu, M. Miura, and K. Kiguchi, "Cocoon spinning behavior in the silkworm, Bombyx mori: comparison of three strains constructing different cocoons in shape," Zoological Science, vol. 16, no. 2, pp. 215223, 1999.

[47] C. Y. Hayashi and R. V. Lewis, "Evidence from flagelliform silk cDNA for the structural basis of elasticity and modular nature of spider silks," Journal of Molecular Biology, vol. 275, no. 5, pp. 773-784, 1998.

[48] J. Magoshi, Y. Magoshi, M. A. Becker, and S. Nakamura, "Biospinning (silk fiber formation, multiple spinning mechanisms)," in Polymeric Materials Encyclopedia, J. C. Salamone, Ed., vol. 1, pp. 667-679, CRC Press, Boca Raton, Fla, USA, 1996.

[49] C. S. Ki, J. W. Kim, H. J. Oh, K. H. Lee, and Y. H. Park, "The effect of residual silk sericin on the structure and mechanical property of regenerated silk filament," International Journal of Biological Macromolecules, vol. 41, no. 3, pp. 346-353, 2007. 

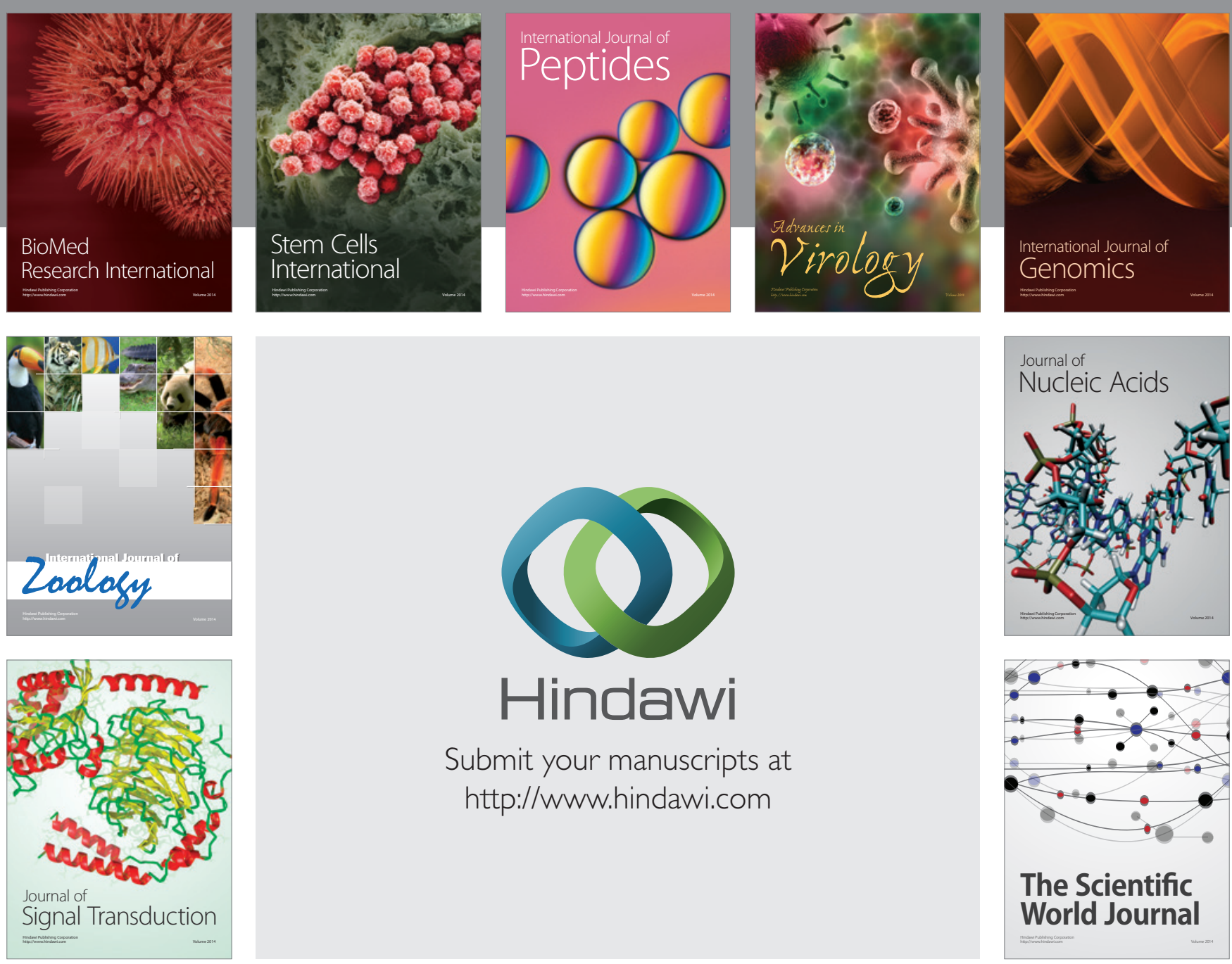

Submit your manuscripts at

http://www.hindawi.com
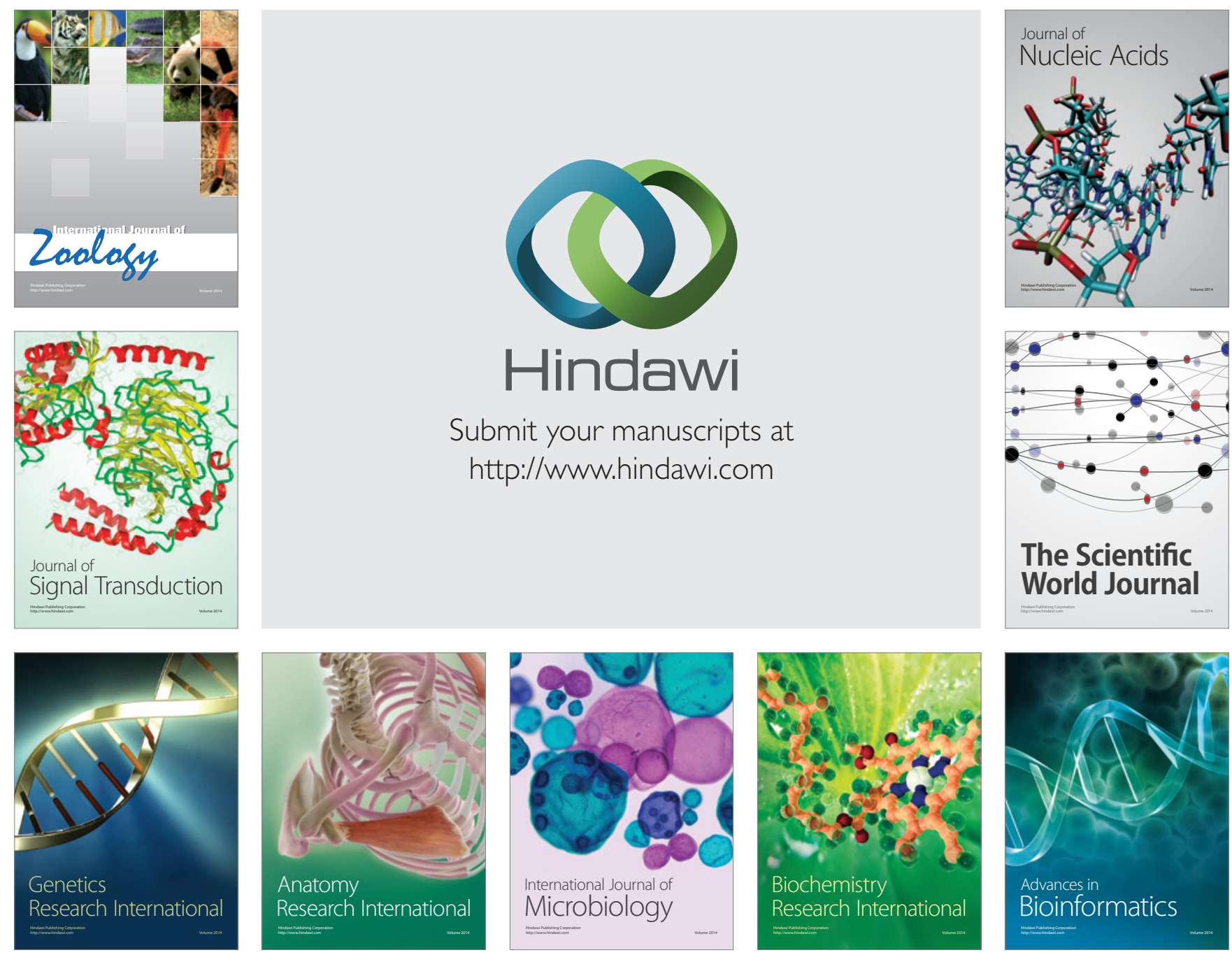

The Scientific World Journal
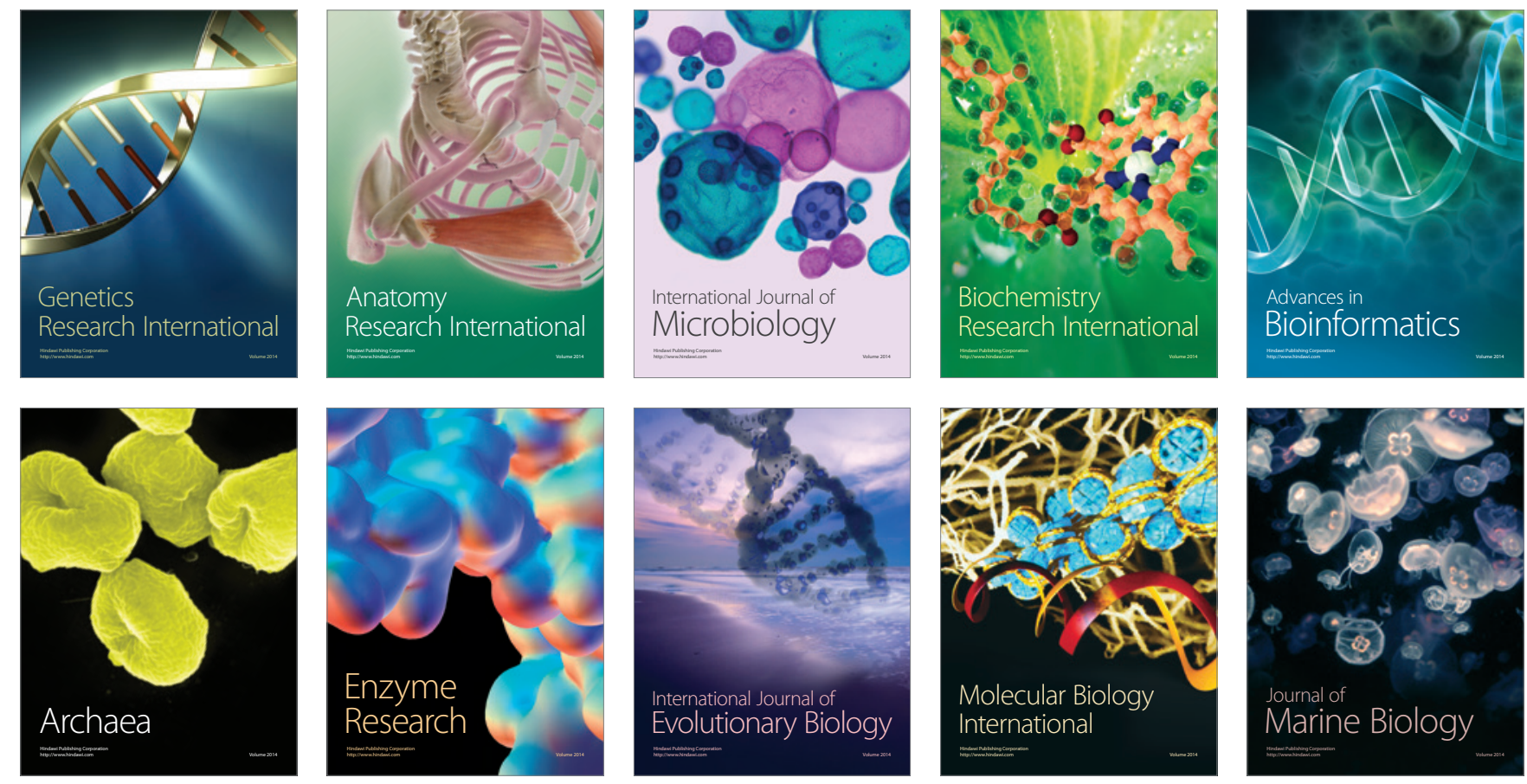